\title{
A INFLUÊNCIA DA ENGENHARIA SEMIÓTICA NA EXPERIÊNCIA DO USUÁRIO DE APLICATIVOS MOBILE: Uma reflexão sobre a relação entre semiose e o desenvolvimento de APPs
}

\author{
THE INFLUENCE OF SEMIOTIC ENGINEERING \\ IN THE USER EXPERIENCE OF MOBILE APPLICATIONS: \\ $A$ reflection on the relationship between semiosis and the development of \\ APPs
}

\author{
João Paulo Carneiro Aramuni \\ Doutorando (2017-2020) \\ Universidade FUMEC \\ joaopauloaramuni@fumec.br \\ Luiz Cláudio Gomes Maia \\ Doutor em Ciência da Informação pela UFMG \\ Universidade FUMEC \\ luiz.maia@fumec.br
}

RESUMO. Este artigo apresenta uma abordagem sobre a influência da engenharia semiótica na experiência do usuário de aplicativos mobile. Uma vez que a semiótica se define como o estudo dos signos, dos processos de significação e como os signos e os significados tomam parte na comunicação, os seus estudos estão atualmente voltados para os processos de comunicação mediada por computador entre designers e usuários de sistema, em seus tempos de interação conjunta. Através dos sistemas de interface, por muitos meios diretos e indiretos, designers dizem aos usuários como eles podem ou devem interagir com o sistema, a fim de adquirir um alcance particular de alvos antecipados pelo momento do designing. A mensagem interativa dos designers para os usuários inclui uma "linguagem de interação" que deverá ser utilizada na comunicação de usuários com o sistema. 0 objetivo deste estudo é ampliar a visão do leitor sobre esta linguagem de interação e a forma como ela é construída no caso de aplicativos móveis. Este estudo contribui com o preenchimento de uma lacuna teórica na compreensão da relação entre semiose e desenvolvimento mobile. Na perspectiva aplicada, a pesquisa oferece contribuições para à comunidade de desenvolvedores de aplicativos móveis quanto à compressão da influência da semiótica na experiência do usuário com a interface do produto desenvolvido.

Palavras-chave: Engenharia Semiótica; Experiência do Usuário; Desenvolvimento Mobile.

ABSTRACT. This paper presents an approach on the influence of semiotic engineering on the mobile application user experience. Since semiotics is defined as the study of signs, meaning processes, and how signs and meanings take part in communication, their studies are currently focused on the processes of computer-mediated communication between designers and system users, in their times of joint interaction. Through interface systems, by many direct and indirect means, designers tell users how they can or should interact with the system in order to acquire a particular range of anticipated targets by the time of designing. The designers' interactive message for users includes an "interaction language" that should be used in the communication of system users. The purpose of this study is to broaden the reader's view on this interaction language and how it is built in the case of mobile applications. This study contributes to filling a theoretical gap in understanding the relationship between semiosis and mobile development. In the applied perspective, the 
research offers contributions to the community of mobile application developers regarding the compression of the influence of semiotics on the user experience with the developed product interface.

Keywords: Semiotic Engineering; User Experience; Mobile Development.

\section{Introdução}

A popularização dos dispositivos portáteis de comunicação sem-fio com possibilidade de conexão à Internet aponta para a incorporação do padrão de vida nômade e indicam que o corpo humano se transformou em um conjunto de extensões ligadas a um mundo cíbrido, pautado pela interconexão de redes e sistemas on e off line. Para além do fetichismo da robotização humana, é fato que em um mundo globalizado e mediado pelas telecomunicações, o corpo conectado às redes torna-se a interface entre o real e o virtual sem que, por isso, denote que nos tornaremos equipamentos de carne obsoletos. Afinal, ao mesmo tempo em que esses corpos são diluídos em uma massa descarnada, feita de informação, essa mesma massa de dados duplica sua existência como telepresença e presença física. (BEIGUELMAN, 2005)

Este estudo é uma reflexão sobre as interfaces digitais entre homens e máquinas, especificamente desenvolvidas para dispositivos móveis. 0 crescimento da base de usuários de dispositivos móveis (celulares, tablets, palms, entre outros) e a ampliação das possibilidades tecnológicas de interação com estes aparelhos, à chamada computação ubíqua, criam constantemente oportunidades para a discussão de novas linguagens e interfaces nestas plataformas.

O estudo de interfaces mobile demanda, no mínimo, o estudo de outros dois contextos. 0 primeiro é o contexto tecnológico de desenvolvimento das máquinas, que dita limites e novas possibilidades em termos de hardware e software. Este contexto influencia e desafia diretamente o designer de interfaces. 0 segundo é o contexto cultural no qual está inserido o "usuário final" da interface e por consequência do dispositivo. Conforme Manovich (2001) pontua, a maneira que o software é desenhado molda a maneira como entendemos o aparelho por trás deles, molda nossa percepção sobre o objeto. Essa proposição de Manovich atribui responsabilidades novas ao desenvolvedor de interfaces: provocar a interação, estimular a capacidade de raciocínio do interator e, em última instância, desenhar a percepção do objeto.

No caso da sociedade pós-industrial, na qual a relação entre instrumentooperador deixou de ser tão binária quanto - “antes os instrumentos funcionavam 
em função do homem; depois grande parte da humanidade passou a funcionar em função das máquinas" (FLUSSER, 2002: 21) - e passou a contar com o conceito de "aparelhos": trata-se de um objeto com funções pré-programa (e isso é o que define), de forma a um leigo conseguir operá-lo e do qual um profissional busca o esgotamento, a superação (FLUSSER, 2002: 23). 0 exemplo ilustrado por Flusser é a máquina fotográfica, pré-programada para diversas funções, que pode ser operada por um leigo ou por um fotógrafo profissional. Aquele geralmente executa registros segundo a predisposição da máquina, e este, por sua vez, busca ultrapassar os limites da máquina e, com isso, retroalimenta a indústria para aperfeiçoar o desenvolvimento de novos modelos.

Esta mesma metáfora é válida também para interação com computadores e pode ser aplicada aos celulares, neste caso não estamos levando em consideração os leigos e profissionais, mas sim, os heavy users e os low users, muito embora o termo user, ou usuário - amplamente usado para designar aquele que interage com um sistema computacional esteja cada vez menos adequado à nossa relação atual com a tecnologia - especialmente no que diz respeito ao uso de celular.

Constantino (2008) corrobora ao dizer que no caso da relação com os celulares, temos que estes dispositivos representam uma mudança significativa na condição de uso, uma vez que a relação do interator-dispositivo é muito mais intensa, já que o aparelho é necessário ou simplesmente intrusivo, criando situações de uso nos mais variados contextos.

Por acreditar que as interfaces terão influência condicional nas nossas atividades sociais, uma vez que estão progressivamente mais presentes $e$ mediando cada vez mais as trocas de informações culturais, me ative a evitar o uso do termo "usuário" - salvo citações - para me referir à pessoa que se relacionará com os códigos através da interface. Isso, pois sou partidário da ideia de que seu uso será tão comum e tão imbricado com as experiências pessoais que precisam ser tratadas assim, como se faz com a energia elétrica ou até mesmo com o ar. Ninguém se refere a um usuário de energia elétrica ou usuário do ar. São pessoas que vão estar em contato com as interfaces tão naturalmente quanto acendem uma luz ou quanto respiram. Não param para pensar nessas atividades - -om exceção do momento em que não as tem. Assim, chamá-las de usuários remeteria a uma situação ultrapassada e antiquada para o contexto que se forma. Isso ressalta ainda mais a relevância das interfaces. A interação com os códigos não pode requerer um conhecimento complexo das pessoas. Tem de se apresentar quase que intuitivamente para que seu uso seja imperceptível e plenamente incorporado à sociedade. (PRADO, 2006: 10). 
A abordagem centrada no usuário levada ao extremo, aliada à sofisticação dos recursos tecnológicos disponíveis para design de interfaces tem confundido mais do que simplificado a vida do usuário comum. Em geral, movidos por pressões mercadológicas, muitos aplicativos móveis são apresentados com todos os tipos de "cosmética" em sua interface. Isso em geral afeta a performance do usuário e adiciona confusão ao já caótico mercado (BARANAUSKAS et al. 2015).

\section{Revisão da literatura}

De acordo com Souza (2005), a Engenharia Semiótica tem sua origem como uma abordagem semiótica para o design de interfaces. Em função do aumento da utilização das mídias digitais, atualmente o conceito de Engenharia Semiótica pode ser entendido como uma teoria semiótica da interação humana X computador (AMORIM, 2016). Para Souza, Barbosa e Prates (2001), a Engenharia Semiótica se concentra na identificação e prevenção de interrupções no processo de comunicação entre designer e usuário por meio uma abordagem, que visa a colocar o designer como interpretante dos problemas e necessidades dos usuários finais, ajudando-os a suprir suas demandas adequadamente. Para isso, o designer deve ter em foco quem são os usuários, quais suas necessidades, o que eles desejam fazer e por quê.

Para Souza (2005), sob a perspectiva da semiótica, a Engenharia Semiótica constrói o elo designer-usuário por via metacomunicação, pois ao projetar uma interface o designer atribui em seu sistema o seu entendimento de quem é seu usuário, qual seu entendimento sobre a necessidade do usuário, além de como e por quais maneiras o usuário prefere suprir sua necessidade. Para a autora, esse processo de comunicação só pode ser considerado como bem-sucedido se os receptores dessa mensagem, quando a interpretarem, entenderem a mensagem do designer e atuarem conforme suas expectativas. Portanto, a comunicação não é apenas um processo de combinação de componentes que fazem sentido para interlocutores e receptores, mas um processo muito mais rico e sutil, que envolve a geração de significado por meio de uma utilização eficiente de recursos e estratégias para tornar o processo de comunicação fluido e sem interrupções. 
Santaella (2007) afirma que as hoje tecnologias computacionais regem as nossas relações profissionais, sociais e impactam diretamente na nossa autoidentidade e vida social.

Segundo a autora, a grande característica das mídias digitais reside na interatividade, pois, agora situados no ciberespaço, não há espaço para os papéis de emissor e receptor, há apenas espaço para um contínuo fluxo de informação. Esses ciberespaços então reconfiguram os modelos tradicionais de comunicação que se dão de maneira unidirecional para um modelo bidirecional em que o antigo receptor também assume o papel de interlocutor:

[...] com a introdução dos microcomputadores pessoais e portáteis, que nos anos 80 já estavam penetrando no mercado doméstico, os espectadores começaram a se transformar também em usuários. Isso significa que começou a mudar aí a relação receptiva de sentido único com o televisor para o modo interativo e bidirecional que é exigido pelos computadores [...]. (SANTAELLA, 2007, p.5).

$\mathrm{Na}$ medida em que a comunicação toma um caráter bidirecional, os interlocutores passam a interagir, deixando de lado uma postura passiva, tomando uma postura mais crítica, dotada de decisões próprias:

[...] Na medida em que o usuário foi aprendendo a falar com as telas, através dos computadores, telecomandos, gravadores de vídeo e câmeras caseiras, seus hábitos exclusivos de consumismo automático passaram a conviver com hábitos mais autônomos de discriminação e escolhas próprias. [...] (SANTAELLA, 2007, p.5).

Para Preece, Rogers e Sharp (2005), atualmente, para a concepção de sistemas interativos, é necessária a formação de equipes multidisciplinares, com indivíduos oriundos das mais diversas áreas, não mais se restringindo à computação. A concepção de sistemas interativos é resultado de uma abordagem centrada no usuário e em suas necessidades, que carecem de um trabalho que percorra desde a análise de tarefas até a concepção do design, a sua avaliação, manutenção, ergonomia e testes de usabilidade. Ao defenderem a concepção de sistemas de interface por meio de uma abordagem centrada no usuário, os trabalhos de Preece, Rogers e Sharp (2005), apesar de enfatizarem design de interação, se aproximam da proposta da Engenharia Semiótica, que visa à codificação de interfaces mais "amigáveis" e intuitivas, com menor grau de frustração e maior sentimento de gratificação por parte do usuário. 
De acordo com Amorim (2016), para a concepção desses sistemas, o designer pode tomar como base signos já inseridos na cultura dos usuários, relacionando-os com o tipo de mensagem que lhes deseja enviar. Nesse processo, o designer deve conhecer, acima de tudo, o que deseja comunicar ao usuário, de modo que o usuário se identifique com o que será proposto por ele e seja capaz de interpretar corretamente a mensagem transmitida. Como esses sistemas são o elo de comunicação entre esses dois pontos, as mensagens enviadas aos usuários devem ser claras e simples, direcionadas para o tema que o designer deseja trabalhar. Uma abordagem clara e simples permite que o usuário entenda a mensagem transmitida e a responda de maneira adequada, enquanto o contrário pode romper o elo de comunicação entre os pontos, desestimulando a utilização desse sistema por parte do usuário.

\section{Metodologia}

Considerando o objetivo proposto para este estudo, que visa identificar as estratégias de uso da engenharia semiótica para melhorar a experiência do usuário e aprimorar o desenvolvimento de aplicativos mobile, a pesquisa classifica-se, quanto aos objetivos, como exploratória. Segundo Gil (2008), a pesquisa exploratória envolve a proporcionar maior familiaridade com o problema (explicitá-lo). Pode envolver levantamento bibliográfico e entrevistas com pessoas experientes no problema pesquisado.

Em relação à abordagem do problema, a pesquisa caracteriza-se como qualitativa. De acordo com Oliveira (2000), o método qualitativo "sempre" foi considerado como método exploratório e auxiliar na pesquisa científica. No entanto, o autor destaca que o novo paradigma da ciência coloca o método qualitativo dentro de outra base de concepção teórica na mensuração, processamento e análise de dados científicos, atribuindo-lhe valor fundamental no desenvolvimento e consolidação da ciência em diferentes áreas.

Quanto aos procedimentos técnicos, a pesquisa caracteriza-se como bibliográfica. Para Gil (2008), a pesquisa bibliográfica é desenvolvida com base em material já elaborado, constituído principalmente de livros e artigos científicos.

\section{Análise e discussão dos resultados}


A literatura sobre engenharia semiótica e design de interfaces ajudou a alcançar os objetivos deste estudo, através da metodologia de pesquisa utilizada, gerando os resultados que serão apresentados a seguir.

\subsection{Influência da engenharia semiótica na experiência do usuário}

O conteúdo da comunicação do designer para o usuário via interface, ou seja, o conteúdo da mensagem da metacomunicação que transmite a intenção de design pode ser expresso de forma sucinta pelo seguinte esquema, proposto pela teoria:

\footnotetext{
"Esta é a minha interpretação sobre quem você é, o que eu entendi que você quer ou precisa fazer, de que formas prefere fazê-lo e por quê. Este é, portanto, o sistema que projetei para você, e esta é a forma como você pode ou deve usá-lo para atingir os objetivos incorporados na minha visão." (Souza, 2005, p. 84)
}

Do ponto de vista da Engenharia Semiótica, portanto, uma boa interface deve conter elementos que facilitem a comunicação desta mensagem (Bim, 2009), ou seja, o conteúdo da mensagem elaborada pelo designer deve ser não ambíguo e compreensível para que o usuário tenha condições de realizar seus objetivos ao receber a mensagem.

Desta forma, comunicabilidade é o critério principal da qualidade de um sistema segundo a Engenharia Semiótica. A definição de comunicabilidade vem sendo refinada ao longo da evolução da teoria. Em Prates et. al (2000) o conceito foi definido como:

"Comunicabilidade é a propriedade que um software tem de transmitir aos usuários, de maneira eficiente e eficaz, a sua intenção de design e seus princípios interativos subjacentes".

A concepção da interação humana $X$ computador como um processo comunicativo torna a Engenharia Semiótica comprometida também com os processos de interpretação e atribuição de significados inerentes a qualquer tipo de comunicação. Uma interação de design comunicada pode ser interpretada de várias maneiras diferentes por usuários diferentes. Os processos comunicativos entre usuários e designers são, portanto, sempre únicos, singulares, imprevisíveis. Cada caso de interação humano-computador é um caso particular de metacomunicação. Para a Engenharia Semiótica a atividade de construção (ou 
elaboração) de uma interface para a interação humano-computador é vista, antes de tudo, como uma engenharia de comunicação.

\subsection{Relação entre semiose e o desenvolvimento de APPs mobile}

As diretrizes estabelecidas pelo estudo dos símbolos e da semiose são válidas para qualquer tipo de sistema, seja ele um software robusto para computador ou um simples aplicativo para celular. Não há nenhuma distinção na literatura de Engenharia Semiótica em relação ao tipo de sistema desenvolvido. Ou seja, os desenvolvedores de aplicativos móveis, e designers, podem adotar as mesmas práticas e conceitos da semiótica seja na construção de sistemas Desktop, Web ou de APPs móveis.

A participação do designer na criação do sistema ainda é negligenciada em algumas culturas organizacionais. Nem todos os gestores de projeto possuem a visão sobre a importância deste ator no processo de desenvolvimento. No caso da construção de aplicativos mobile não é diferente, a equipe necessita do processo criativo do designer para a elaboração da interface.

Por melhor que seja a noção semiótica dos programadores, a experiência e o know-how de um designer não deve ser subestimada. A presença deste profissional é de vital importância para o sucesso do projeto e para uma melhorar experiência do usuário com o sistema.

O designer de interfaces deve possuir conhecimentos que transitam não somente nas tecnologias, ferramentas e técnicas do design, mas também em tudo aquilo que o usuário final precisa para trabalhar bem com o sistema. Ou seja, concentrar-se na usabilidade com foco no público-alvo da aplicação.

\section{Considerações finais}

Este trabalho buscou, além dos objetivos propostos, oferecer sua contribuição acadêmica, a partir de uma perspectiva mais abrangente, integradora, em busca da melhoria na compreensão das questões que envolvem o uso da engenharia semiótica no desenvolvimento de aplicativos mobile. 0 trabalho atingiu os objetivos estabelecidos, que eram colaborar como um instrumento de conscientização a respeito do tema proposto, mostrando como a engenharia 
semiótica pode ser utilizada para melhorar a experiência do usuário de aplicativos mobile.

Desta forma, este artigo procurou abordar a engenharia semiótica de maneira a esclarecer sua relação com o desenvolvimento de APPs mobile e exaltar sua importância para a satisfação do usuário final.

Como apontado no decorrer deste estudo, não há literatura extensa sobre a relação explícita entre engenharia semiótica e desenvolvimento mobile. São oportunidades para avanços aos quais os pesquisadores e profissionais podem se dedicar.

Como sugestão para trabalhos futuros, pode-se apontar a necessidade de metodologias, padrões, ferramentas ou práticas de desenvolvimento de aplicações voltadas exclusivamente à semiologia e suas particularidades.

\section{Referências}

AMORIM, M. G. G. CIDADANIA E TECNOLOGIA: favorecendo a comunicabilidade entre a população belo-horizontina e o seu legislativo tendo por base estudos de Engenharia Semiótica e desenvolvimento de um protótipo de aplicativo para smartphones. Dissertação (Mestrado em Sistemas de Informação e Gestão do Conhecimento da Universidade FUMEC). 2016. Disponível em:<http://www.fumec.br/revistas/sigc/article/view/4643/2520>. Acesso em: 10 jul. 2018.

BARANAUSKAS M. C. C; ROSSLER F.; OLIVEIRA O. L. Uma abordagem semiótica d̀ análise de interfaces: um estudo de caso. 2015. Campinas - SP. Disponível em: <https://goo.gl/P2SWKU>. Acesso em: 10 jul. 2018.

BARBOSA, Simone Diniz Junqueira; PRATES, Raquel de Oliveira. A semiotic engineering approach to user interface design. Knowledge-Based Systems, v. 14, p. 461-465, 2001. Disponível em: <http://www-di.inf.pucrio.br/ clarisse/docs/2001desouzaKBSspecial-issue.pdf>. Acesso em: 4 set. 2016.

BEIGUELMAN, Giselle. Admirável mundo cíbrido, 2005. Disponível em: http://netart.incubadora.fapesp.br/portal/Members/gbeiguelman/Textos. Acesso em: 10 jul. 2018.

BIM, S. Obstáculos ao ensino dos métodos de avaliação da Engenharia Semiótica. Rio de Janeiro, 2009. 181 p. Tese de doutorado - Departamento de Informática, Pontifícia Universidade Católica do Rio de Janeiro.

CONSTANTINO, J. M. Interfaces Mobile: Metodologia de desenvolvimento de modelos de navegação e análise de inadequação de heranças da comunicação analógica. Dissertação (Mestrado em Comunicação e Semiótica da PUC-SP). 2008. Disponível

em: 
<https://tede2.pucsp.br/bitstream/handle/5138/1/Juliana\%20Maria\%20Consta ntino.pdf>. Acesso em: 10 jul. 2018.

FLUSSER, Vilém. Filosofia da Caixa Preta. Ensaios para uma futura filosofia da fotografia - Rio de Janeiro: Relume Dumará, 2002.

GIL, A. C. Como elaborar projetos de pesquisa. São Paulo: Atlas, 2008.

MANOVICH, Lev. The Language of New Media. Cambridge, Mass: MIT Press, 2001.

OLIVEIRA, Claudionor dos Santos. Metodologia científica, planejamento e técnicas de pesquisa: uma visão holística do conhecimento humano. São Paulo: LTR, 2000.

PRADO, Renato S. de A., Arquitetura de Interface. Análise de formas de organização da informação na interação entre pessoas e códigos. 2006. 107 f. Dissertação (Mestrado em Comunicação e Semiótica) - Pontifícia Universidade Católica de São Paulo, São Paulo.

PRATES, R. O.; de SOUZA, C.S; BARBOSA, S. D. J. A method for evoluating the communicability of user interfaces. Interactions. 2000.

PREECE, Jenifer; ROGERS, Yvonne; SHARP, Helen. Design de interação: além da interação homem-computador. Porto Alegre: Bookman, 2005.

SANTAELlA, Lucia. Potenciais e desafios para a comunicação e inovação. Comunicação \& Inovação, São Caetano do Sul, v. 8, n. 4, 2007. Disponível em: <http://seer.uscs.edu.br/index.php/revista_comunicacao_inovacao/article/view/ 667>. Acesso em: 10 jul. 2018.

SOUZA, Clarisse Sieckenius de. Semiotic engineering: bringing designers and users together at interaction time. Interacting with Computers, v. 17, n. 3, p. 317-341, maio $2005 . \quad$ Disponível em: <http://www.sciencedirect.com/science/article/pii/S0953543805000202>. Acesso em: 10 jul. 2018. 